\title{
Copyright Information Resource Management in Nigeria: and the Way Forward
}

\author{
Okoroma Francisca Nwakaego \\ Kenneth Dike Library, University of Ibadan, Ibadan, Nigeria
}

Email address:

frankaonyeka@yahoo.com

To cite this article:

Okoroma Francisca Nwakaego. Copyright Information Resource Management in Nigeria: and the Way Forward. International Journal of Intelligent Information Systems. Vol. 9, No. 6, 2020, pp. 61-66. doi: 10.11648/j.ijiis.20200906.11

Received: July 28, 2020; Accepted: September 29, 2020; Published: December 31, 2020

\begin{abstract}
The enrichment of the national cultural heritage is directly linked to the level of protection given to literary and artistic works. The higher the level of protection, the greater the number of each country's intellectual output. This calls for an effective copyright information resource management in every nation and organization to optimize access to relevant information on copyright in order to curb the rate of infringement. This paper seeks to address the copyright information resource management in Nigeria, and the way forward. Questionnaire instrument was used for data collection. The last two questions on the questionnaire were open-ended questions, designed to enable the respondents freely express their views and suggestions. The findings identified the benefits of copyright information resource management, both to the authors and the users; include the inhibition of infringement as it delivers quick access to copyright related information in a dynamic and effective way. This is due to the fact that many acts of infringement on copyright are as a result of ignorance on the part of users. The findings further highlighted that copyright information resource management facilitation is dependent on putting the right people in positions of authority, setting up committee in each institution to monitor and establish standards in order to ensure quality assurance in the system, and keeping tracks of publications of each university's scholar.
\end{abstract}

Keywords: Copyright, Information Resource, Management, Universities, Nigeria

\section{Introduction}

In order to achieve an environment which enables information sharing all over the world, it is very imperative to achieve an environment where copyright information resources are efficiently and effectively managed. Information resources management (IRM) includes the basic infrastructure management, underlying technology, standards and protocols, access models and finally the user management which is the ultimate purpose of any knowledge management process. Information is an asset, a very important resource in the Knowledge Society and its management goes beyond the traditional Library management. It includes management of change, time and electronic sources, along with traditional collection management aspects. Information resource management is a philosophical and practical approach to managing information. Considering that information is a valuable resource to be managed like other resources, IRM contributes directly to the accomplishment of organizational goals and objectives. It provides an integrated approach to managing the entire life cycle of information: starting from the creation, distribution, to archiving or even the destruction of the information in order to maximize the overall usefulness of information. Information resource management (IRM) is defined as "a comprehensive approach to planning, organizing, budgeting, directing, monitoring and controlling the people, funding, technologies, and activities associated with acquiring, storing, processing, and distributing data to meet a business need for the benefit of the entire enterprise" [2]. IRM provides an integrated view for the management of the entire life cycle of information from creation to archiving or destruction. Information resource management addresses the efficient and effective handling of information resources 
and the resulting information assets. Three main events that triggered the inception of IRM are: Information explosion, Proliferation of paper and Extensive use of information handling technologies. The basic aspects of IRM are infrastructure management, information management (which includes copyright information management), knowledge management and user management. The focus of this work is on copyright Information resource management.

Copyright is a universal concept and a form of protection provided by the laws of any sovereign state. It is a legislation backed right for creation of work [16]. Copyright originated from the fact that anything that is created is an extension of self. Therefore it should be protected from indiscriminate use by the general public [5]. Infringement on Copyright is the abuse and violation, piracy or theft of copyright holder's exclusive right through unauthorized usage [6]. It has been reported that piracy of intellectual property is Nigerian's greatest challenge in business [13]. This could however be highly eliminated throw access to copyright related information resources.

Copyright information resources management deals with the capturing, organizing and disseminating of information on the appropriate utilization of copyrighted content. Rebecca focused on who should be responsible for copyright information management, including what their education credentials should be, where the activity should organizationally reside, and what responsibilities the individual should have [14]. Her results suggest that hiring an intellectual property attorney is the most important component to building a copyright program that will be respected. Someone with a Juris Doctorate as copyright officer will help to provide other resources in support of copyright information management. The reasons behind this preference is that a lawyer will respond to copyright queries better, including having an awareness of how to read and interpret court decisions as he understands how the legal system works, increasing the legitimacy of information conveyed, and ensuring that the information is not coming from someone who is not fully prepared to respond.

It should be noted that Nigeria had a Copyright Council established to see to the administration of Copyright, which was reviewed in 1999 [4]. The Council was saddled with the following responsibilities:

1. Responsible for all matters affecting copyright in Nigeria as provided for in this Act;

2. Monitoring and supervising Nigeria's position in relation to international convention and advise government thereon;

3. Advice and regulating conditions for the conclusion of bilateral and multilateral agreements between Nigeria and any other country;

4. Enlightening and informing the public on matters relating to copyright;

5. Maintaining an effective data bank on authors and their works; and

6. Responsible for such other matters as relates to copyright in Nigeria, as the Minister may from time to time, direct [4].

Presently Nigeria is at the vague of amending her copyright Act, and the NCC has published a draft copy bill in 2015, which is yet to be enacted into law [3].

The copyright law in Nigeria was managed by the Nigerian Copyright Commission (NCC) which was a corporate body established by the Federal Government under the Ministry of Culture and Social Welfare [12]. The Council was given the mandate for all copyright matters in Nigeria, such as the enforcement of the copyright law, enlightening and educating the general public on issues related to copyright, mandating those who use works of Nigerian authors to pay enough royalties, as well as representing the interests of all Nigerian artists in the world wide copyright issues and keeping records of all the authors in Nigeria.

The only government approved rights management society for the print medium in Nigeria is the Reproduction Rights organisation of Nigeria (Repronig) [8]. Repronig was formally established on 3rd November 2003. It was mandated by law to collect, negotiate and share royalties to relevant stakeholders. Repronig's international relationship with a network of associations was developed to guard the rights of its stakeholders and members. Members of Repronig include consortia of professional associations in the creative arts e.g. the Society of Nigerian Artists (SNA), Association of Nigerian Authors (ANA). Both the Nigerian Guild of Editors (NGE) and the Nigerian Union of Journalist (NUJ) are also expected to join.

Some of the challenges confronting the Nigerian Copyright Commission (NCC) in the fight against piracy are poor funding; inadequate mobility and technological knowhow [11]. Again the International Intellectual Property Alliance (IIPA) reported that the EFCC generally regards copyright matters as a secondary issue. Therefore the Nigerian Copyright Commission needs to put more effort in the areas of enlightenment and enforcement of the copyright law [12]. This is very necessary as majority of infringers on copyright claim ignorance of the Nigerian copyright statute and the existence of the Nigerian Copyright Commission The authors added that the Nigerian Copyright Commission should vigorously educate the people on the grave implications of the abuse of copyright law through workshops, seminars and conferences as majority of the respondents asserted ignorance on the awareness of copyright as well as having ever been harassed for making photocopy of published works. Ezekude added that the NCC has intensified its fight for copyright since 2010 [9].

Furthermore, there is high level of ignorance, and different levels of perception on intellectual Property Right by the right owners, including the supportive institutions such as the college authorities, the universities and the guilds or associations of business center owners [10]. The authors noted that it is practicable to give license to users of works protected by rights as long as these users are brought to the holistic knowledge of the moral, legal and spiritual 
implications of their present activities.

It should be noted that infringement on copyright by any individual is punishable with five years imprisonment or a fine of one thousand naira for every infringed copy of a work for which he is responsible. Thereafter, all the copies of the work, plates, master tapes, machines and other equipment in the possession of the infringer are destroyed or surrendered to the owner of the copyright [1].

The afore has brought to the lime light the need for an effective copyright information resource management, to enable the public to be well informed on the subject and issues relating to copyright. Literature focused more on the application of copyright law, including various changes and updates that have occurred $([3,7])$. Literature exposes high level of ignorance on both parts of the users and the copyright owners, which has resulted into high level of infringement on copyright. There is dearth of literature relating to copyright information resource management. and none actually focused on copyright information resource management in Nigeria.

Therefore the main objective of the study is to investigate copyright information resource management in Nigeria.

Research Questions:

1. What are the benefits of copyright information resource management?

2. How can copyright information resource management be enhanced in Nigeria?

3. How can copyright information resource management be facilitated within the university campuses?

\section{Methodology}

The population used in the study comprised of 150 academic staff of University of Ibadan, Nigeria (U.I.) and the senior staff, who by virtue of working experience in the university environment poses sufficient knowledge on copyright information management in their departments. The main instrument used in this study was questionnaire. This is in consideration of the users' large number; hence the questionnaire was suitable for gathering enormous quantity of data from large population within the quickest possible time. The last two questions on the questionnaire were openended questions, designed to enable the respondents freely express their views and suggestions. The researcher made use of both primary and secondary data. Various resources and publications in the library relevant to the study formed the secondary data. While the questionnaire that was used to collect data from the respondents, formed the primary data, the data collected was reported using simple frequencies and percentage.

\section{Research Findings}

\subsection{Demographic Representation of the Respondents}

Table 2 shows that majority of the respondents are aged between 20 - 30 years $(43.3 \%)$, followed by, $31-40$ years
(28\%), while only 1 respondent is above the age of 60 .

Table 2 revealed that many departments were represented, a total of 26 departments in university of Ibadan were represented in the study, with LARIS and Statistics departments towering with 24 (16\%) and 20 (13.3\%) respectively, while Agric Economics, Animal Science, Biology, Crop Production, Medicine, Microbiology, Political science and Special Education were the least represented with $1(.7 \%)$ respondent each.

Table 1. Distribution of respondents by age.

\begin{tabular}{lll}
\hline Age & Frequency & Percent \\
\hline 20-30 years & 65 & 43.3 \\
31-40 years & 42 & 28.0 \\
41-50 years & 25 & 16.7 \\
51-60 years & 5 & 3.3 \\
61-above & 1 & .7 \\
Total & 138 & 92.0 \\
Non response & 12 & 8.0 \\
\hline
\end{tabular}

Table 2. Distribution of respondents by department.

\begin{tabular}{lll}
\hline Department & Frequency & Percent \\
\hline Valid & 29 & 19.3 \\
Agric & 7 & 4.7 \\
Agric Economics & 1 & .7 \\
Animal Science & 1 & .7 \\
Biology & 1 & .7 \\
Chemistry & 12 & 8.0 \\
Crop Production & 1 & .7 \\
Economics & 10 & 6.7 \\
Education Management & 4 & 2.6 \\
geology & 8 & 5.3 \\
history & 2 & 2.7 \\
Institute of African Study & 2 & 1.3 \\
jaja & 2 & 2.7 \\
LARIS & 24 & 16.0 \\
Law & 2 & 1.3 \\
Library & 5 & 3.3 \\
Medicine & 1 & .7 \\
Microbiology & 1 & .7 \\
Petroleum engineering & 2 & 1.3 \\
physics & 2 & 1.3 \\
political science & 1 & .7 \\
psychology & 2 & 1.3 \\
security unit & 2 & 2.7 \\
Sociology & 4 & 2.7 \\
Special Education & 1 & .7 \\
Statistics & 20 & 13.3 \\
Teacher Education & 2 & 1.3 \\
Total & 150 & 100.0 \\
\hline & & \\
& &
\end{tabular}

\subsection{Research Questions 1}

What are the benefits of copyright information resource management?

Table 3 highlighted the opinion of the respondents on the 
benefits of copyright information resource management.

Table 3. General opinion on the benefits of copyright information resource management (CIRM).

\begin{tabular}{|c|c|c|c|c|c|c|}
\hline \multirow[b]{2}{*}{ Statements } & \multicolumn{6}{|c|}{ Frequency } \\
\hline & $\begin{array}{l}\text { Strongly } \\
\text { Disagree }\end{array}$ & Disagree & Neutral & Agree & $\begin{array}{l}\text { Strongly } \\
\text { Agree }\end{array}$ & $\begin{array}{l}\text { Non } \\
\text { respondent }\end{array}$ \\
\hline CIRM is for quick access to copyright related information & $1(.65 \%)$ & $4(3.3 \%)$ & $13(9 \%)$ & $59(42 \%)$ & $67(44.7 \%)$ & $6(4 \%)$ \\
\hline CIRM will prevent infringement on copyright & $6(4 \%)$ & $6(4 \%)$ & $7(4.5 \%)$ & $36(24 \%)$ & $92(61.3 \%)$ & $3(2 \%)$ \\
\hline CIRM is beneficial to the society; to know their boundaries. & $2(1.3 \%)$ & $13(9 \%)$ & $17(12 \%)$ & $62(41.3 \%)$ & $52(35 \%$ & $4(2.6 \%)$ \\
\hline CIRM will create awareness on the rules of copyright & $2(2.3 \%)$ & $4(3.3)$ & $18(12.2 \%)$ & $80(53.3 \%)$ & $45(30 \%)$ & $2(1.3 \%)$ \\
\hline CIRM will help to enforce copyright laws & $2(1.3 \%)$ & $3(2 \%)$ & $13(9 \%)$ & $59(42 \%)$ & $67(44.7 \%)$ & $6(4 \%)$ \\
\hline CIRM will help authors to have full benefit of their work & $5(3.5 \%)$ & $11(7.5 \%)$ & $8(5 \%)$ & $53(35.3 \%)$ & $66(44 \%)$ & $7(4.5 \%)$ \\
\hline CIRM will ultimately encourage international trade. & $5(3.5 \%)$ & $9(6 \%)$ & $27(18.5 \%)$ & $55(36.7 \%)$ & $45(30 \%$ & $9(6 \%)$ \\
\hline CIRM enhances the protection of cultural identity. & $3(2 \%)$ & $9(6 \%)$ & $26(18 \%)$ & $53(35.3 \%)$ & $50(35 \%)$ & $9(6 \%)$ \\
\hline CIRM will ultimately enhances creativity and innovation & $8(6.6 \%)$ & $4(3.3 \%)$ & $10(7 \%)$ & $82(56.7 \%)$ & $42(30 \%)$ & $4(2.6 \%)$ \\
\hline
\end{tabular}

Table 3 revealed that copyright information resource management (CIRM) is very beneficiary to both the authors and the society at large. Majority of the respondents 126 $(87 \%)$ indicated that CIRM makes for quick access to copyright related information, while 127 (85\%) opined that CIRM will prevent infringement on copyright. Most of the respondents (over $80 \%$ ) indicated that CIRM is beneficial to the society as it enable them to know their boundaries in matters relating to copyright. Again 125 (83\%) and 107 (71\%) of the respondents respectively ascertained that CIRM will create awareness on the rules of copyright as well as enhance copyright protection.

Furthermore many of the respondents 126 (87\%) were of the opinion that CIRM will help to enforce copyright laws, and $119(79 \%)$ of them were of the view that CIRM will help authors to have full benefit of their works. Also while 100 (67\%) persons identified that CIRM will ultimately encourage international trade, $103(70 \%)$ and $124(87 \%)$ respectively claimed that CIRM will lift up the protection of cultural identity and ultimately enhance creativity and innovation.

\subsection{Research Questions 2}

How can copyright information resource management be enhanced in Nigeria?

This research question was addressed with open-ended questions.

Table 4. Opinions of the respondents on how copyright information resource management can be enhanced in Nigeria.

\begin{tabular}{lll}
\hline Suggestions & Frequency & Percent \\
\hline Adequate funding. & 18 & 12.0 \\
Sanctions should be passed on defaulters. & 34 & 23 \\
Putting of right people in power. & 21 & 14.0 \\
Setting up of a committee to monitor things. & 30 & 20.0 \\
Providing copyright board in each institution. & 24 & 16.0 \\
\hline
\end{tabular}

Table 4 revealed the respondents' response to the question "how can copyright information resource management be enhanced in Nigeria". While $18(12 \%)$ of the respondents ascertained that adequate funding are prerequisite in facilitating copyright information resource management in Nigeria, 34 (23\%) persons advocated for sanctions to be passed on defaulters. Again, some of the respondents 30 $(20 \%)$ opined that there is need to set up a committee to monitor things and $21(14 \%)$ opined that putting the right people in position of authority is very crucial to avoid corrupt practices, while some others $24(16 \%)$ indicated the need to have a copyright board in each institution.

\subsection{Research Questions 3}

How can copyright information resource management be facilitated within the university campuses?

Table 5. Suggestions on how copyright information resource management can be facilitated within the universities.

\begin{tabular}{lll}
\hline \multicolumn{1}{c}{ Suggestions } & Frequency & Percent \\
\hline $\begin{array}{l}\text { Proper record of publications by the } \\
\text { university scholars. }\end{array}$ & 19 & 12.7 \\
$\begin{array}{l}\text { Various organizations on campus should be } \\
\text { carried along. }\end{array}$ & 20 & 13.3 \\
$\begin{array}{l}\text { Awareness campaigns. } \\
\begin{array}{l}\text { Adequate funding. } \\
\text { Maximum support from the parent }\end{array}\end{array}$ & 41 & 27.3 \\
institution/other stake holders. & 21 & 16.0 \\
\hline
\end{tabular}

Table 5 represents the responses to the open-ended questions of the questionnaire that seek opinion on how copyright information resource management can be enhanced in universities in Nigeria. Some of the respondents 19 (12.7\%) reported the need for proper record of publications by the university scholars, $20(13.3 \%)$ ascertained that carrying along the various organizations on campuses, on the need for the establishment and sustainability of CIRM is very crucial. Again $41(27.3 \%)$ of the respondents indicated that awareness campaign is necessary for community members to identify with the mission and goals of CIRM. On the other hand, 24 (16\%) persons proposed for adequate funding by the university sponsors while $21(14.0 \%)$ indicated the need for maximum support from the parent institution and other stake holders. 


\section{Discussion}

The findings revealed that copyright information resource management is of tremendous benefit to the authors as well as various users of information resources, as it delivers quick access to copyright related information in a dynamic and effective way. For the authors, the benefits include the prevention of infringement on their right as intellectual property owners. This is due to the fact that many acts of infringement on copyright are as a result of ignorance on the part of users. This agrees with literature that majority of infringers on copyright claim ignorance of the Nigerian copyright statute and the existence of the Nigerian Copyright Commission [17]. As users of copyrighted materials access relevant information on the subject, ignorance is eliminated so infringement will be drastically reduced. Again CIRM will help to enforce copyright laws through proper monitoring of publications and identifying offenders. Since no one would like to be sanctioned, users will adhere to the rules thereby enabling authors to have full value for their works.

To the society, CIRM will enable members of the society to know their boundaries in matters relating to copyright through awareness programmes created by CIRM on both the rules and benefits of copyright. Armed with the knowledge that copyright is not devised to shortchange users but for the benefit of all, users will be more cautious not to violate the rules of copyright. This will lower the level of infringement and encourage more creative works for the advancement of the society. Therefore, CIRM will ultimately enhance creativity and innovation, lift up the protection of cultural identity and encourage international trade.

The enhancement of copyright information resource management in Nigeria and within the universities depends on a number of factors, such as; adequate funding. Sufficient funding will not only help in the procurement of cutting edge facilities, and personnel for the efficient and effective management of the resource centers, but will as well provide resources to embark upon appropriate projects and programmes (e.g. awareness programme) as dimed necessary from time to time. The findings advocated that putting the right people in position of authority is very crucial to avoid corrupt practices, and the need to set up a copyright board in each institution. Putting people of proven integrity to man the affairs of CIRM system will in no small scale advance the CIRM forward, due to there will not be issues of diversion of public fund and other resources for personal use. This factor needs to be critically considered, especially in the developing world like Nigeria where there are numerous cases of corrupt practices amongst people in power. There is also a dear need to set up a committee to monitor and establish standards in order to ensure quality assurance in the system, and identify defaulters for sanction.

Furthermore, information resource management can be enhanced in universities in Nigeria through proper record of publications of each university scholar. By keeping track of publications in each university, the CIRM centers can be guided in their work and this will facilitate rational decisions. Awareness campaign is also necessary for community members to identify with the mission and goals of CIRM. These, coupled with adequate funding and maximum support from the parent institution/other stake holders are necessary towards a sustainable CIRM system.

\section{Conclusion}

A country's development depends most solemnly on the creativity of the citizenry, and the encouragement of national creativity is sine qua non for societal advancement. Therefore, for creativity and innovation that leads to national advancement not to be impaired, it is very imperative for a nation to protect the intellectual property of her citizens from undue exploitation. To have an efficient copyright information resource management system, there must be optimal cooperation from the government, university management system, authors, publishers and users of information around the world to support the establishment and sustainability of information resource management system.

\section{References}

[1] Ayanyemi, O. O. (2007). The Copyright System: Nigerian Perspective. A Paper Presented at the One-Day Sensitization Seminar/Wor kshop on Mastering International Standards and BibliographicControl in Book Publishing Organized by the National Library of Nigeria Oyo State Branch held at the National Library of Nigeria, Oyo State Branch, Ibadan.

[2] Bruce, R. L., Charles, A. S. and Rainer, R. K. (2015). An empirical assessment of Information resource management constructs. Journal of Management System Vol 12 (1).

[3] Chuma-Okoro, H. (2018) Nigeria Copyright reform and implications for access to teaching and learning materials in the digital age. The African Journal of Information and $\begin{array}{lll}\text { Communication } & \text { (AJIC), } & 22,\end{array}$ https:/doi.org/10.23962/10539/26172

[4] Copyright (Amendment) Decree, No 42 (1999). Laws of the Federation of Nigeria http://www.nigerialaw.org/Copyright \%20(Amendment) $\% 20$ Decree $\% 20$ No\%204 2\%20of\%201999.htm

[5] Cornish (2004) Copyright interpreting the law for library, archives and information services. London Faceted Publishing.

[6] Copyright Office, United States (2012). Fair use. Retrieved from http://www.copyright.gov/fls/f1 102.html

[7] Crews, K. D. (2006). Copyright law for librarians and educators: Creative strategies and practical solutions (2nd ed.). Chicago: American Library Association.

[8] Egonwa, O. D (2005). Copyright in Nigeria's tertiary institutions. Paper presented at the $4^{\text {th }}$ Nigeria International Book fair on Publishing in indigenous languages.

[9] Ezekude, A. (2012). Anti piracy drive field result. WIPO Magazine. 
[10] International Intellectual Property Alliance (IIPA) (2008). IIPA Report, published by the Nigerian Copyright Commission

[11] Muneja, P. S. and Ndenje-Sichalwe, E. (2016) Institutional repository initiatives in Tanzania: opportunities and challenges. University of Dar es Salaam Library Journal, Vol. 11 (2); pp 74-92.

[12] Nwogu, M. I. (2014). The challenges of the Nigerian Copyright Commission in the fight against copyright piracy in nigeria. Global Journal of Politics and Law Research Vol. 2, No. 5, pp. 22-34, Nigerian Copyright Commission, Historical Background of NCC, Available at http://www.copyright.gov.ng/historicalbackground.

[13] Okilagwe A. O. (2001) Book Publishing in Nigeria; pg 143178.
[14] Onyinye, E. (2013). Nigeria: Piracy Nigerian greatest challenge in business Osanyintunyi, S. (nd) Effect, of piracy in Nigeria. Available at http://www.ccsenet.org/jp/

[15] Rebecca S. Albitz (2013) Copyright Information Management and the University Library: Staffing, Organizational Placement and Authority. The Journal of Academic Librarianship 39 429-435.

[16] U.S. Copyright Office (2000) Copyright Basics (Circular): Espanol, September 2000 http://www.copyright.gov/circs/circ1.html\#wci/

[17] Wahab A. A., Modupeola A. A. and Bolanle A. A. (2015). Copyright infringement and photocopy services among university students and teachers in Nigeria. International Journal of Arts \& Sciences, ISSN: 1944-6934: 08 (01): 463472. 